\title{
Papillary carcinoma of the thyroid in a thyroglossal cyst-a rare incidental finding
}

\begin{abstract}
Papillary thyroid carcinoma (PTC) arising from a thyroglossal duct cyst is very rare. PTC usually presents as a slow-growing, painless thyroid mass or a solitary nodule in the neck. We intend to report a rare case of 47 year old male, who presented with a progressively increasing midline neck swelling for the last 4 years. On examination, the mass was cystic without any solid nodule. No palpable neck nodes ware present. A clinical diagnosis of thyroglossal duct cyst was made. Ultrasonography showed a single large lobulated cystic mass, with foci of calcification. Sistrunk procedure was followed to excise the lesion. Histopathological examination of the excised mass showed variable sized thyroid follicles, areas of calcification and foci of atypical cells with features of papillary thyroid carcinoma. The patient was treated with 50 Gy of Co-60 radiotherapy and 6 cycles of adjuvant chemotherapy with Cisplatin $50 \mathrm{mg} / \mathrm{m}^{2}$. He is doing well after 12 months of follow up period without any metastasis.
\end{abstract}

Volume 8 Issue 2 - 2020

\section{Kafil Akhtar, Jowairiah Hasan, Sumbul Warsi, Shafaque Zabin}

Department of Pathology, Jawaharlal Nehru Medical College, Faculty of Medicine, Aligarh Muslim University, Aligarh (UP), India

\section{Correspondence: Dr. Kafil Akhtar, Professor, Department of Pathology, Jawaharlal Nehru Medical College, Aligarh Muslim University, Aligarh (U.P), India, Email drkafilaktar@gmail.com}

Received: March 16, 2020 | Published: June 30, 2020

Keywords: papillary carcinoma, sistrunk procedure, thyroglossal duct cyst, ultrasonography

Abbreviations: PTC, papillary thyroid carcinoma; TDC, thyroglossal duct cyst

\section{Introduction}

Thyroglossal duct cyst (TDC) is the most common congenital anomaly of the thyroid gland. ${ }^{1}$ Normal thyroid gland descends along the thyroglossal duct, which is an embryonic midline duct originating from the foramen cecum. TDC is usually located in the mid of the neck. $^{2}$ A failure of regression of the thyroglossal duct may cause cysts to develop. ${ }^{3}$ Carcinomas rarely arise from a TDC, are usually locally invasive, without any known predilection for metastasis. TDC carcinoma is common in the third and fourth decades of life and rare in children and adolescents. ${ }^{4}$ The most common carcinoma arising in TDC is papillary carcinoma, which constitutes $75.0 \%-85.0 \%$ of all thyroid cancers. ${ }^{5}$ Papillary carcinoma presents as a thyroid mass or a solitary cystic neck lump in cases of metastatic disease. ${ }^{4,5}$ We intend to report a rare case of 47 year old male, who presented with a progressively increasing midline cystic neck swelling, which was diagnosed as papillary carcinoma arising in a thyroglossal cyst.

\section{Case report}

A 47 year old male came to the Surgical Clinics with complaints of progressively increasing midline neck swelling for the last 4 years. He had no history of pain, dysphasia, hoarseness of voice, fever, loss of appetite and loss of weight. He also had no history of any systemic illness and family history. On examination, a well-defined cystic, non tender, swelling, $8 \mathrm{~cm} \times 6 \mathrm{~cm}$ in size was seen in the mid of the neck. The overlying skin appeared to be normal with no signs of sinus or fistula. The mass was fixed to the underlying structures, was compressible, non-pulsatile, non-fluctuant and moving with deglutition. No neck nodes were palpable. A provisional diagnosis of a thyroglossal cyst was given. Fine needle aspiration cytology showed features of a cystic lesion. X-ray chest was normal. On ultrasonography, a large lobulated cystic mass with hyper and hypoechoeic areas with focal calcification was seen. There was no abnormality detected in routine hematologic and urine investigations. Surgical excision of the cystic swelling with sistrunk's procedure was performed. Grossly, the specimen was $10.4 \mathrm{~cm} \times 6 \mathrm{~cm} \times 3.8 \mathrm{~cm}$ in size, with multinodular and well capsulated external surface. Cut section showed a multiloculated cystic swelling with foci of solid grey white areas with focal papillary excrescences. Microscopic examination showed a multiloculated cystic lesion with variable sized thyroid follicular epithelial cells and foci of calcification. Focal areas of cellular atypia was noted within tumor cells exhibiting ground glass nuclei Figure $1 \& 2$. Immunohistochemical staining showed diffuse moderate intensity cytoplasmic positivity of Pan Cytokeratin Figure 3. A histopathologic impression of papillary carcinoma of thyroid in a thyroglossal cyst was made. Postoperative period was uneventful and our patient was absolutely all right. 50 Gy of Co-60 radiotherapy and adjuvant chemotherapy with Cisplatin $50 \mathrm{mg} / \mathrm{m}^{2} \times 6$ cycles was administered. Our patient is doing well after 12 months of follow up.

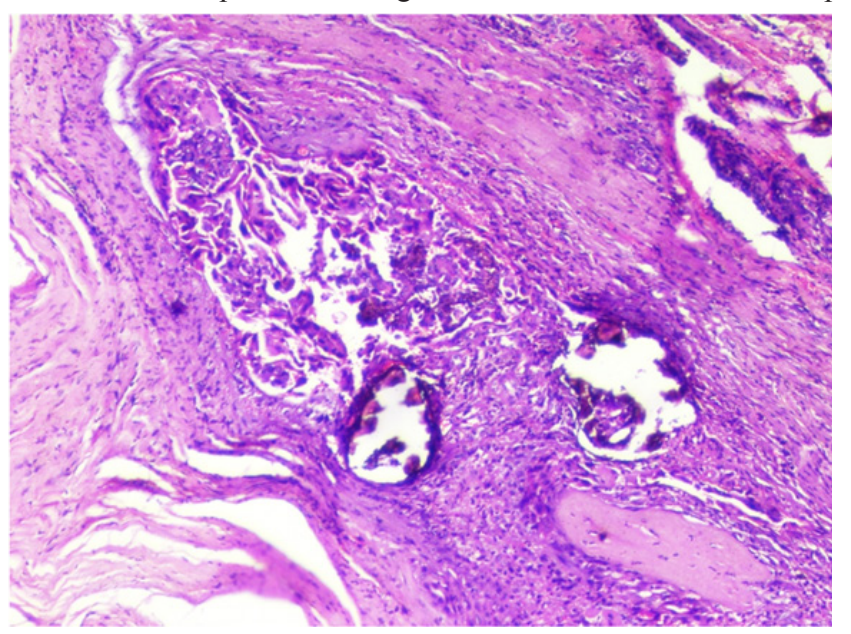

Figure I Microscopic examination shows a multiloculated cystic lesion with variable sized thyroid follicular epithelial cells and foci of calcification. Focal areas of cellular a typical was noted within tumor cells exhibiting ground glass nuclei. Hematoxylin and Eosin $x I 0 X$. 


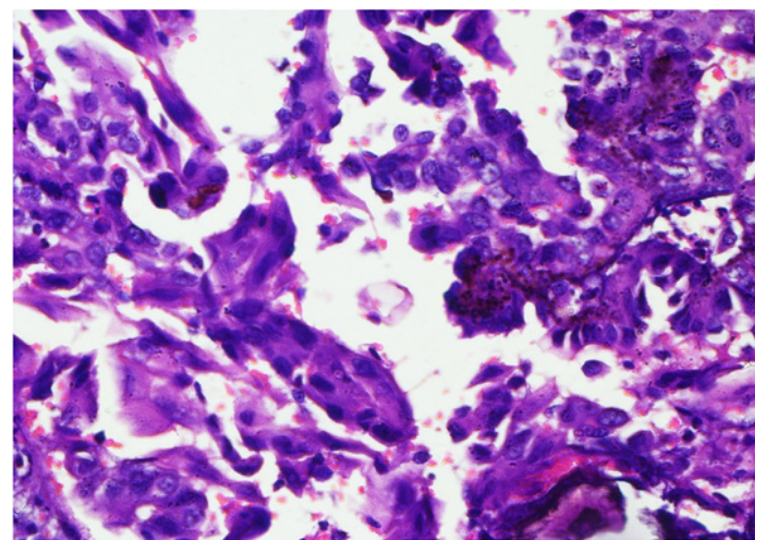

Figure 2 Microscopic examination shows clusters of atypical thyroid follicular epithelial cells exhibiting ground glass nuclei and foci of calcification. Hematoxylin and Eosin $x 40 X$.

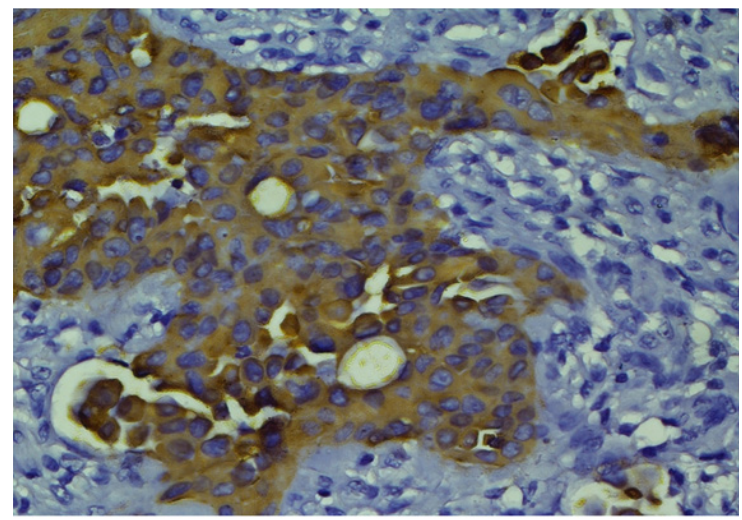

Figure 3 Immunohistochemical section shows diffuse moderate intensity cytoplasmic positivity of pan cytokeratin. Pan CK x40X.

\section{Discussion}

Most of the thyroglossal duct remnants are benign; however, a small percentage of them undergoes neoplastic change. ${ }^{5}$ TDC carcinoma is uncommon and the incidence varies from 0.7 to $1.0 \%{ }^{6}$ TDC carcinoma usually affects the women, with male: female ratio of 1.2:2. ${ }^{7}$ Papillary thyroid carcinoma (PTC) is the most common malignancy found in a TDC $(80.0 \%)$, followed by follicular or mixed papillary follicular carcinoma $(9.0 \%)$, squamous cell carcinoma (5.0\%), adenocarcinoma (2.0\%) and anaplastic carcinoma $(1.0 \%){ }^{8,9}$ PTC can present clinically as a solitary cystic neck mass without any thyroid lesion. In our case, there was no palpable lesion in the thyroid gland. The initial symptoms of thyroglossal duct cyst carcinoma are indistinguishable from a benign thyroglossal duct cyst. ${ }^{10,11}$ It is important to note that this extrathyroidal neck cyst mimics benign cystic lesions of the neck like branchial cyst, thyroglossal duct cyst, dermoid cyst, epidermoid cyst or cystic hygroma presentation. ${ }^{10,11}$ A rapid increase in the size of the growth may indicate a malignant change. ${ }^{12}$ Malignancy in TDS should be suspected, if there is dysphasia, dysphonia, associated lymphadenopathy and the mass is not moving freely on deglutition. ${ }^{12,13}$ However, in our case, the mass was fixed to the underlying structures but moving with deglutition. A high index of clinical suspicion of malignancy should be kept in patients $>40$ years old and history of radiation exposure to the neck. ${ }^{12}$ Thus, initial evaluation of an adult patient who presents with a cystic neck mass should include a detailed clinical history, a thorough head and neck examination, as well as FNAC of the mass and imaging. ${ }^{9,10}$
Computed tomography scan, neck nuclear magnetic resonance imaging and ultrasound may show a solid heterogenous mass and may play an important role in pre-operative diagnosis, staging of malignancy and in the planning of treatment. ${ }^{14}$ The surgical excision of a thyroglossal duct remnant is a Sistrunk's procedure, with removal of the thyroglossal duct cyst, part of the hyoid bone and the remaining atretic part of the duct. ${ }^{15}$ Underwood et al., ${ }^{15}$ analyzed 62 cases of TDC and suggested that Sistrunk procedure is adequate for most patients with a low rate of recurrence. ${ }^{15}$ Currently, there are no clear guidelines for the management of cystic neck mass. ${ }^{10,11}$ Studies have reported a near total or total thyroidectomy or lobectomy in thyroid cancer of size between 1-4 cm, without extrathyroidal extension and lymph nodal involvement. ${ }^{14,15}$ Thyroid lobectomy alone is a sufficient treatment for small unifocal intrathyroid carcinoma in the absence of prior head and neck radiation, familial thyroid carcinoma or clinically detectable cervical nodal metastases. ${ }^{15}$ The prognosis of papillary carcinoma arising in TDC is excellent, with an overall survival rate of $95.6 \%$ at 10 years. ${ }^{14,15}$ The postsurgical follow up of patients includes a thorough annual clinical examination, ultrasound of the neck and thyroid profile.

\section{Conclusion}

PTC can sometimes present as a cystic neck mass. So all patients with a solitary cystic neck mass must be treated with a high index of clinical suspicion and routine ultrasonography and FNAC must be performed.

\section{Acknowledgments}

None.

\section{Conflicts of interest}

None of the authors declares conflicts of interest.

\section{Funding}

None.

\section{References}

1. Torcivia A, Polliand C, Ziol M, et al. Papillary carcinoma of the thyroglossal duct cyst: report of two cases. Rom J Morphol Embryol. 2010;51(4):775-777.

2. Aghaghazvini L, Mazaher H, Sharifian H, et al. Invasive thyroglossal duct cyst papillary carcinoma: a case report. J Med Case Rep. 2009;3:9308.

3. Chuathong A, Ouawathanamongkol S, Maipang T, et al. An unusual presentation of thyroglossal duct cyst associated with papillary thyroid carcinoma. Int $J$ Case Rep Images. 2011;2(6):12-15.

4. Godara R, Marwah S, Ahuja V, et al. Papillary carcinoma of thyroid in a thyroglossal cyst: a case report and literature review. J Clin Med. 2009;4:238-240.

5. Ishay A, Elmalah I, Luboshitzky R. Papillary carcinoma in a thyroglossal duct cyst. Isr Med Assoc J. 2008;10(4):312-313.

6. Al-Ashaa Y, Hefny AF, Joshi S, et al. Papillary thyroid carcinoma presenting as a lateral neck cyst. African Health Sci. 2011;11(2):296-300.

7. Carter Y, Yeutter N, Mazeh H. Thyroglossal duct remnant carcinoma: beyond the sistrunk procedure. Surg Oncol. 2014;23(3):161-166.

8. Kalyani R, Hebbar A, Murthy S. Primary papillary carcinoma arising in thyroglossal duct cyst: a rare case report. Nat J Lab Med. 2015;4(3):2729. 
9. Chala A, Alvarez A, Sanabria A, et al. Primary papillary carcinoma in thyroglossal cysts. case reports and literature review. Acta Otorrinolaringol Esp. 2016;67(2):102-106.

10. Bakkar S, Biricotti M, Stefanini G. The extent of surgery in thyroglossal cyst carcinoma. Langenbecks Arch Surg. 2017;402(5):799-804.

11. Choi Y, Kim TY, Song DE. Papillary thyroid carcinoma arising from a thyroglossal duct cyst: a single institution experience. Endocrine $J$. 2013;60(5):665-670.

12. Tharmabala M, Kanthan R. Incidental thyroid papillary carcinoma in a thyroglossal duct cyst-management dilemmas. Int J Surg Case Rep. 2013;4(1):58-61.
13. Pietruszewska W, Wagrowska-Danilewicz M, Józefowicz-Korczyńska M. Papillary carcinoma in thyroglossal duct cyst with uninvolved thyroid. case report and review of the literature. Arch Med Sci. 2014;10(5):10611065.

14. Chrisoulidou A, Iliadou P, Doumala E. Thyroglossal duct cyst carcinomas: Is there a need for thyroidectomy? Hormones(Athens). 2013;12(4):522528.

15. Underwood HJ, Williams DM, Kundel A. Papillary thyroid carcinoma within thyroglossal duct cyst: case report and review of literature. JSM Head Neck Cancer Cases Rev. 2016;1(2):1006-1009. 